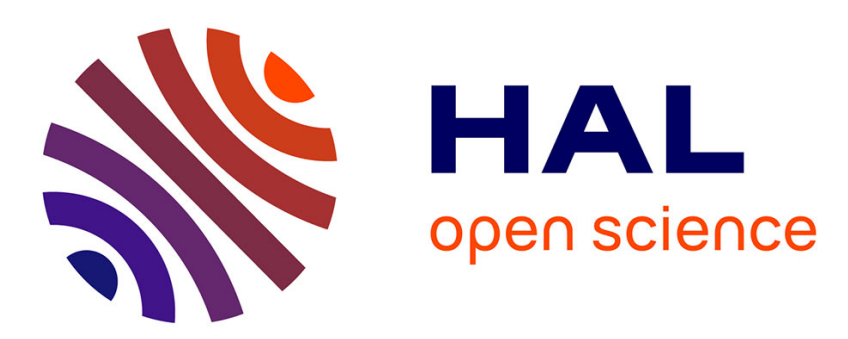

\title{
Vulnerability: from the conceptual to the operational using a dynamical system perspective
}

Charlène Rougé, Jean-Denis Mathias, Guillaume Deffuant

\section{To cite this version:}

Charlène Rougé, Jean-Denis Mathias, Guillaume Deffuant. Vulnerability: from the conceptual to the operational using a dynamical system perspective. Environmental Modelling and Software, 2015, 73, pp.218-230. 10.1016/j.envsoft.2015.07.018 . hal-02601943

\section{HAL Id: hal-02601943 \\ https://hal.inrae.fr/hal-02601943}

Submitted on 16 May 2020

HAL is a multi-disciplinary open access archive for the deposit and dissemination of scientific research documents, whether they are published or not. The documents may come from teaching and research institutions in France or abroad, or from public or private research centers.
L'archive ouverte pluridisciplinaire HAL, est destinée au dépôt et à la diffusion de documents scientifiques de niveau recherche, publiés ou non, émanant des établissements d'enseignement et de recherche français ou étrangers, des laboratoires publics ou privés. 
Author-produced version of the paper published in

Environmental Modelling \& Software, November 2015, vol.73, 218-230.

Original paper available at http://www.sciencedirect.com (Elsevier).

DOI : $10.1016 /$ j.envsoft. 2015.07 .018

\title{
Vulnerability: from the conceptual to the operational using a dynamical system perspective
}

\author{
Charles Rougé $^{1,2}$, Jean-Denis Mathias ${ }^{1}$ and Guillaume Deffuant ${ }^{1}$
}

July 29,2015

\begin{abstract}
This work proposes to address a lack of conceptual consensus surrounding the concept of vulnerability, by fostering a minimal definition as a measure of potential future harm, and by basing it on a stochastic controlled dynamical system framework. Harm is defined as a normative judgment on a trajectory. Considering all the possible trajectories from an initial state leads to the definition of vulnerability indicators as statistics derived from the probability distribution of harm values. This framework 1) promotes a dynamic view of vulnerability by eliciting its temporal dimension and 2) clarifies the descriptive and normative aspects of a system's representation. As illustrated by a simple model of lake eutrophication, this work makes vulnerability a precise yet flexible concept which fosters discussion on trade-offs between vulnerability sources, and also on adaptation. Links with economics, with control theory, and with algorithmic methods such as dynamic programming are highlighted. Keywords: Vulnerability, Indicators, Harm, Robustnessvulnerability trade-offs, Adaptation, Lake eutrophication
\end{abstract}

\footnotetext{
${ }^{1}$ Irstea, UR LISC Laboratoire d'ingénierie des systèmes complexes, 9 avenue Blaise Pascal - CS 20085, 63178 Aubière, France

${ }^{2}$ Université Laval, Département de génie civil et de génie des eaux, Pavillon Adrien-Pouliot, 1065 avenue de la Médecine, Québec G1V 0A6, QC, Canada
} 


\section{Introduction}

This work proposes an operational definition of vulnerability, based on a stochastic dynamical system framework which accounts for its uncertain evolution and for the actions that may be undertaken to impact it. Vulnerability is defined in a most general way as a measure of potential future harm. It is an oft-used concept in the literature dealing with the potential negative impacts of natural hazards and social and environmental change. However, vulnerability concepts and tools originate from several different communities (Adger, 2006; Eakin and Luers, 2006; Miller et al., 2010). Consequently, there is a lack of consensus around conceptual definitions of the term and this breeds vagueness (Hinkel, 2011). Thus, despite the existence of similar operational protocols, unified frameworks in or across research fields are largely missing (Costa and Kropp, 2012).

This work does not ambition to study vulnerability under all its aspects, nor to review the many branches of scientific literature in which it is a meaningful concept. Rather, it aims at constructing a formal framework around a very general definition of the term, and at connecting it to some of the

existing literature on vulnerability in environmental modeling and social and ecological systems. Making such connections seems particularly relevant in a context of global change, in which computational frameworks to assess vulnerability to various natural hazards have been burgeoning in recent years (e.g. Balica et al., 2013; Giupponi et al., 2013; Lardy et al., 2014; Martin et al., 2014; Papathoma-Köhle et al., 2015); yet each of these models relies on a slightly different understanding of what vulnerability is conceptually .

The minimal definition of vulnerability as a measure of potential future harm comes from a formal analysis of the term (Wolf et al., 2013). It is the lowest common denominator in most vulnerability definitions in the literature (Hinkel, 2011). To our knowledge, our framework constitutes the second attempt at mathematically formalizing the concept of vulnerability after that by Ionescu et al. (2009), who argue that such a formalization is warranted for several reasons, namely making vulnerability assessments systematic, clarifying the concepts and their interpretations, avoiding analytical inconsistencies and practical omissions, and facilitating the development of computational approaches. These motives stress that formalization is useful regardless of the case at hand, and whether or not a dynamical system formulation is available.

We propose to start with a very general mathematical formulation, and then to interpret it in the context of vulnerability literature. We argue that this approach provides both a formal basis and a great flexibility for the discussion of vulnerability concepts. Indeed, mathematics remain a nonambiguous reference for discussing concepts, especially in cases in which they may be interpreted in several relevant ways. In that sense, flexibility appears as a prerequisite to bridging the gap between conceptual definitions and their many possible operational translations. In the case of vulnerability, flexibility is sorely needed because of the wide range of fields that use the concept, as it is present in the climate change literature (see e.g. Turner II et al., 2003; Adger, 2006; Parry et al., 2007), in the natural hazards literature (e.g. Birkmann, 2006; Fuchs, 2009; Peduzzi et al., 2009), in the socialecological systems (SES) literature (see e.g. Peterson, 2002; Anderies et al., 2007; Rodriguez et al., 2011; Rives et al., 2012), but also in the development economics literature (see e.g. Christiaensen and Boisvert, 2000; Hoddinott and Quisumbing, 2003; McCulloch and Calandrino, 2003; Béné et al., 2012).

Besides, a controlled stochastic dynamical system perspective also provides a link between vulnera- 
bility and the capacity to act. This connection is often explicitly highlighted in the literature (Turner II et al., 2003; Gallopín, 2006; Smit and Wandel, 2006), to the extent that vulnerability is often associated with a limited ability to act (McCarthy et al., 2001; Adger, 2006; Parry et al., 2007). Furthermore, the notion of control is associated to vulnerability through so-called robustness-vulnerability trade-offs (Anderies et al., 2007; Rodriguez et al., 2011) which arise when increasing robustness to a set of shocks inevitably leads to increased vulnerability to another set of shocks.

Following this brief presentation on our main motivations for proposing a mathematical approach to vulnerability definition, the rest of this work is as follows. Section 2 presents the dynamical system framework that we propose, and this starts with a paragraph that completes this introduction by outlining this framework and showing how available literature backs our choices (Section 2.1). Then, Section 3 illustrates these concepts using a simple dynamical system model of lake eutrophication (Carpenter et al., 1999), while Section 4 discusses them; both Sections also illustrate how policy design and the system's representation dynamically impact one another. Section 5 provides concluding remarks.

\section{A dynamical system framework for vulnerability}

\subsection{Overview of the framework}

Let us imagine a healthy-looking economy or ecosystem right before it crashes, when the unemployment rate is still low, or biodiversity still high. In such cases, the present situation is good but is about to deteriorate dramatically. Conducting an assessment of the system based on a single stage in the present or near future is like taking a snapshot of it: it gives a static view of the system. By contrast, observing its trajectory over a longer time-frame is more relevant since it gives a dynamic view of it and may help anticipate its undesirable evolution.

This observation suggests that vulnerability indicators can be more relevant when encompassing an entire time frame, rather than a single date. Yet, time is only one of four types of variables one needs to consider within a general stochastic controlled dynamical system formulation. The three other are the system's state, the actions - called control within the mathematics of control theory - implemented

to manage it, and the uncertainty that affects it. Upon interpretation of that formulation in the context of vulnerability literature, we propose that vulnerability concepts are related to one another by abstraction over one of these categories of variables, either by aggregation - such as for time - or by selection. Our presentation of the framework is to start with all four categories of variables, then abstract them one at a time until only the initial state remains, as detailed in Figure 1 and justified from the literature in the remainder of this section.

Section 2.2 proposes a starting point through a representation of a system at a given stage $t$ that is both descriptive and normative. Its descriptive side relies on a general dynamical system formulation of a single-stage evolution from stage $t$ to $t+1$. This formulation is very similar to that of Ionescu et al. (2009) in their attempt at proposing a formal approach for vulnerability, but it explicitly considers the role of uncertainty as a determinant for the future state of the system, along its present state and the control actions that are implemented. Section 2.2 also makes the normative side explicit compared to previous formulations, through the introduction of a single-stage harm function associated to a state 


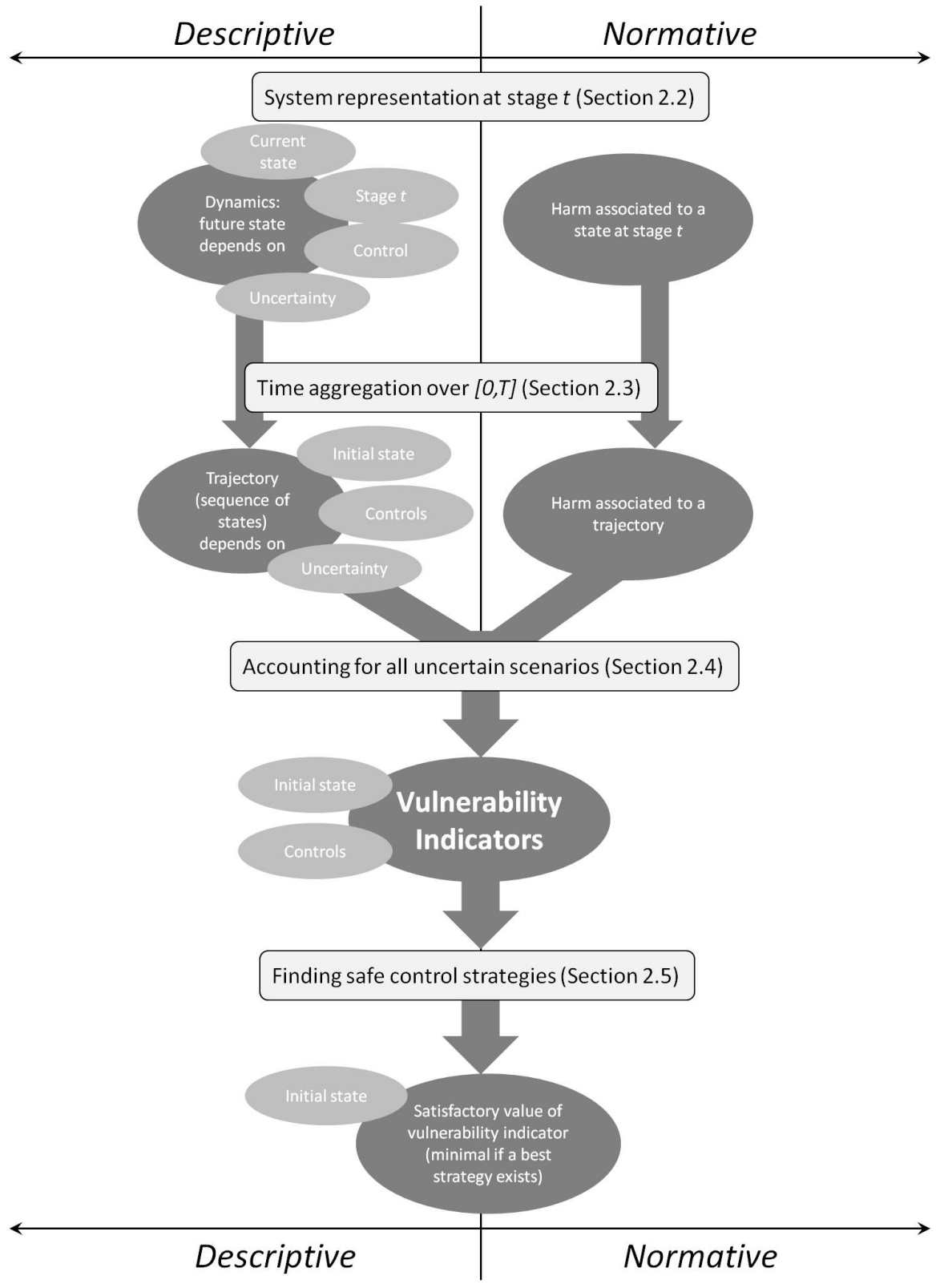

Figure 1: Schematic representation of the proposed framework, which proceeds through successive aggregations to define vulnerability concepts. This figure announces the flow of Section 2. Light-gray ellipsoids highlight the variables the elements in dark-gray ellipsoid depend on. 
at stage $t$.

Then, Section 2.3 aggregates over time to provide a system's representation over the entire period $[0, T]$ of interest, whereas Ionescu et al. (2009) mainly base their discussion on vulnerability on evolutions over a single time step. Vulnerability of an entity depends on uncertain dynamics over time (Wolf et al., 2013), a fact that is often overlooked or kept implicit (Liu et al., 2008), even though vulnerability to a natural hazard may be apparent only long after the event's occurrence (Menoni et al., 2002; Lesnoff et al., 2012). As demonstrated by the development economics literature, acknowledging that vulnerability should be measured over several future periods can help learn about its determinants (Christiaensen and Boisvert, 2000). For example, a household's trajectory over several periods must be taken into account in order to measure chronic poverty and vulnerability to poverty (McCulloch and Calandrino, 2003). Hence the need for a framework centered on the idea of possible future trajectories to which harm values are associated. Trajectories depend on controls and uncertainty over $[0, T]$, but also on the initial state of the system, as illustrated by the concept of path dependence (Preston, 2013).

After that, Section 2.4 considers all the uncertain scenarios over $[0, T]$ to propose an operational definition of vulnerability. Indeed, each uncertain scenario yields a different trajectory, so one cannot assess vulnerability from only one of the possible trajectories. Instead, the possible values of future harm are considered through the occurrence probabilities of these possible trajectories, leading to obtaining a probability distribution function (pdf) of these harm values. Then, a relevant statistic derived from this pdf is a measure of potential future harm, in other words vulnerability. Though it may seem like a strong choice, aggregating harm values from all trajectories into a single vulnerability indicator is advocated by previous formal analyses of the concept of vulnerability (Ionescu et al., 2009; Wolf et al., 2013).

Finally, Section 2.5 draws connections between vulnerability indicators and the search of appropriate control policies for vulnerability minimization and avoidance. This is achieved by selecting one or several control policies among all possible options. Once a policy is chosen, vulnerability only depends on the initial state. There are two ways of choosing an appropriate policy (Ionescu et al., 2009): through vulnerability minimization, or by choosing policies that keep vulnerability below a reference value. In the latter case, that reference value may be chosen to reflect stakeholder's preferences. It then explicitly connects vulnerability with the notion of threshold it is often associated to (e.g. Luers et al., 2003; Luers, 2005; Béné et al., 2011), and it separates what is satisfactory from what is not. Yet, that reference value may also be related to vulnerability assessed assuming a baseline policy. Then, finding a policy that lowers vulnerability compared with this baseline is associated with adaptation (e.g. Luers et al., 2003; Ionescu et al., 2009; Sandoval-Solis et al., 2011).

\subsection{System representation at a single stage}

\subsubsection{System dynamics}

We consider a system and its uncertain and controlled dynamics. This system can for instance be a SES, but the framework is applicable to any system that evolves with time. For a given current stage $t>0$, the transition to the next stage $t+1$ is given by the following discrete-time equation:

$$
x(t+1)=f(t, x(t), u(t), w(t))
$$


The time-dependent function $f$ determines the transition between two stages. $x(t)$ is the vector of state variables describing the system at stage $t$, and belongs to a state space noted $\mathbb{X}$. Meanwhile, $u(t)$ is the vector representing the controls that are decided at stage $t$ by stakeholders to influence the state. It is chosen from a set $u_{a}(t, x)$ of available controls. $w(t)$ is the vector representing the uncertainty and variability that affect the system at stage $t$. It therefore aims at taking into account hazards, shocks and stresses, whatever their nature.

\subsubsection{Single-stage harm}

Harm is introduced as a normative judgment on the "badness" of a system's state at a given moment (Hinkel, 2011). It is intrinsically a subjective notion (Ionescu et al., 2009; Wolf et al., 2013). In other words, it reflects a value judgment on a state $x(t)$, so that different stakeholders within a given SES may have different views on which states ought to be identified as harmful, and to what extent they are harmful. This leads to defining a single-stage harm function $h$ :

$$
(t, x) \mapsto h(t, x)
$$

Although it is not a general necessity, it may often be convenient to assume that single-stage harm is a quantity that is never negative, but can be equal to zero if it can be considered that no harm is being done to the system.

\subsection{System representation over a time horizon}

\subsubsection{Trajectories}

Rather than by a single state transition between two consecutive stages, we are interested in a system's evolution at a discrete set of stages $t=0,1, \ldots, T-1, T$ indexed by integer values. They define a time frame of interest $[0, T]$. Within this time frame, a state trajectory $X$ is the following sequence of states $^{1}$ :

$$
X=(x(0), x(1), \ldots, x(T))
$$

$X$ shall be more simply called trajectory in the remainder of this work. The approach of assessing vulnerability using all the states of a system trough its evolution can be associated with the word "dynamic", as opposed to the "static" approach of using only a state $x(t)$ at a given stage $t$.

If $X$ represents an actual sequence of system states, then through equation (1), it depends on the values $u(t)$ and $w(t)$ at every stage, so definitions for sequences of controls and uncertainty vectors are warranted. Similar to De Lara and Doyen (2008), we call scenario the sequence of events $W=$ $(w(0), w(1), \ldots, w(T))$. The space of all possible scenarios is noted $\Omega$. Probabilistic assumptions about uncertainty are needed, and they are detailed in Appendix A. They lead to assume the existence of a probability $\mathbb{P}$ defined over $\Omega$. Besides, we assume that this probability has a pdf which we note $p(W)$. One should keep in mind that any dynamical representation of a system may not take into account all the possible scenarios, nor evaluate correctly their probability of occurrence, so that no pdf can be considered a complete representation of uncertainty (Carpenter et al., 2008). A policy $U$ associates to

\footnotetext{
${ }^{1}$ A notation not to be confused with that for a random variable, generally in bold: $\mathbf{X}$.
} 


\begin{tabular}{c|c||c|c}
\multicolumn{2}{c||}{ At stage $t$} & \multicolumn{2}{c}{ Over the period $[0, T]$} \\
Name & Notation & Name & Notation \\
\hline Control & $u(t)$ & Policy & $U$ \\
Uncertainty & $w(t)$ & Scenario & $W$ \\
State & $x(t)$ & State trajectory & $X$ \\
Single-stage harm & $h(t, x(t))$ & Harm & $H(X)$ \\
\hline
\end{tabular}

Table 1: Summary of notations at stage $t$, and their counterparts taken over the entire period $[0, T]$.

all stages $t$ and states $x$ a control $u(t, x)$. The set of all the policies $U$ available within a horizon of $T$ is noted $U_{a}(T)$.

Noting $x_{0}=x(t=0)$ the initial state, the triplet $\left(x_{0}, U, W\right)$ defines, according to equation (1), a unique sequence of states. Thus, when a trajectory is associated to such a triplet, we note this trajectory, $X\left(x_{0}, U, W\right)$.

\subsubsection{Harm on a trajectory}

According to Wolf et al. (2013), harm is defined by associating a harm value to an evolution. Therefore, this work defines a harm function $H$ that associates a harm value $H(X)$ to any sequence of states $X$ - regardless of whether it has been associated to a triplet $\left(x_{0}, U, W\right)$ previously or not. Similar to single-stage harm, this notion of harm contains the idea that two trajectories can be compared, and it is both subjective and normative. In fact, the relationship between the harm function $H$ and singlestage harm which is similar to that between $X$ and $x(t)$ : Table 1 summarizes the notations defined at stage $t$ and their counterparts defined over $[0, T]$.

In practice, since harm $H(X)$ along a trajectory may arguably be viewed as a very abstract notion, it can be convenient to define it directly as a function of $(T+1)$ single-stage harm values $h(t, x(t))$ computed on each state along the trajectory. It seems natural to assume that $H(X)$ is an increasing function of each of the $T+1$ single-stage harm values ${ }^{2}$.

\subsubsection{Examples of harm function}

There is a virtually infinite number of ways to build $H$ by aggregating single-stage harm values into a single scalar value. Yet, here we only show three classical way of aggregating a set of values into a single one: 1) through average/summation, 2) through a binary assessment with respect to a critical value or threshold, or 3) through a worst-case approach.

A most straightforward way to assess harm along a trajectory from single-stage harm values $h(t, x(t))$ is to sum these values and form the total harm function, analogous to a total cost:

$$
H_{S}(X)=\sum_{t=0}^{T} h(t, x(t))
$$

Then, another classical measure of harm is through a boolean $H_{\theta}$ which value depends on whether single-stage harm is kept below a threshold level $\theta$ at all times. It is more classically expressed as an

\footnotetext{
${ }^{2}$ In the sense that for any $X_{1}=\left(x_{1}\right)$ and $X_{2}=\left(x_{2}\right)$, if $\forall t \in[0, T], h\left(t, x_{1}\right) \leq h\left(t, x_{2}\right)$, then $H\left(X_{1}\right) \leq H\left(X_{2}\right)$.
} 
indicator of whether the system's trajectory leaves a desirable region at some point:

$$
H_{\theta}(X)=\left\{\begin{array}{lll}
1 & \text { if } & \exists t \in[0, T], x(t) \notin K_{\theta}(t) \\
0 & \text { if } \quad \forall t \in[0, T], x(t) \in K_{\theta}(t)
\end{array}\right.
$$

where $K_{\theta}(t)$ is the set of desirable states, also called constraint set, which regroups states for which single-stage harm is below $\theta$ :

$$
K_{\theta}(t)=\{x \in \mathbb{X}, h(t, x) \leq \theta\}
$$

Recall that $\mathbb{X}$ was defined the state space in Section 2.2.1. $K_{\theta}(t)$ delimits a set of states that can have any shape. As thus, it generalizes the notion of threshold, which most commonly are hyperplanes splitting the state space in two. Yet, it keeps the same function as a threshold, since it separates more desirable states from less desirable ones.

Finally, the worst-case approach consists in measuring harm as the maximal value of single-stage harm during $[0, T]$. This defines $H_{\max }$, a measure of harm severity along the trajectory:

$$
H_{\max }(X)=\max _{t \in[0, T]} h(t, x(t))
$$

One example of field where the above harm indicators are commonly used is that of water resources planning and management(Hashimoto et al., 1982; Moy et al., 1986; Loucks, 1997; Kjeldsen and Rosbjerg, 2004; Sandoval-Solis et al., 2011). For instance, $H_{\max }$ would measure the maximal amount by which a threshold is not met, e.g., the maximum water supply shortage. The only difference is that in the water resources literature, harm severity $H_{\max }$ is evaluated over a failure period when a performance criteria is not met, rather than over a fixed period $[0, T]$. Yet, similar to the present work, the harm functions this literature defines serve as a basis for the definition of vulnerability indicators, which is the focus of the next Section.

\subsection{Vulnerability for a given policy}

\subsubsection{Definition}

For a given harm function $H$ and given initial state $x_{0}$ and policy $U$, one gets a pdf of harm values. We operationally define a vulnerability indicator $V_{H}\left(x_{0}, U\right)$ as a statistic on this pdf of harm values.

Indeed, if we consider an initial state $x_{0}$ and a policy $U$, then for each scenario $W$, there is a unique trajectory $X\left(x_{0}, U, W\right)$, to which a harm value $H\left(X\left(x_{0}, U, W\right)\right)$ is assigned. Since we define vulnerability as a measurement of potential future harm, assessing vulnerability for $x_{0}$ and $U$ supposes to consider harm from all these trajectories, as well as the probability of occurrence of these trajectories.

The above definition virtually leads to the definition of an infinity of vulnerability indicators for a given system. Trying to enumerate them would be beyond the scope of this work; instead, what follows focuses on giving examples of families of common vulnerability indicators. Similar to Section 2.3.3, these indicators aggregate a probability distribution of harm values into a statistic through 1) average/summation, 2) a binary assessment with respect to a critical value or threshold, or 3) a worst-case approach. 


\subsubsection{Average or expected vulnerability indicators}

Vulnerability may be expressed as the expected (or average) value of future harm, computed over the probability distribution of harm values. This is the family of expected vulnerability indicators $V^{E}$ :

$$
V_{H}^{E}\left(x_{0}, U\right)=E\left[H\left(X\left(x_{0}, U, W\right)\right)\right]
$$

where $E$ is the expectation operator for probability distributions, defined over the space $\Omega$ of all scenarios. If the pdf over the scenarios is continuous, then using the density $p(W)$ equation (8) becomes:

$$
V_{H}^{E}\left(x_{0}, U\right)=\int_{W \in \Omega} H\left(X\left(x_{0}, U, W\right)\right) p(W) d W
$$

Alternatively, if this pdf is discrete, then $p(W)>0$ only for a discrete set of scenarios $\Omega_{d} \subset \Omega$, and we have:

$$
V_{H}^{E}\left(x_{0}, U\right)=\sum_{W \in \Omega_{d}} H\left(X\left(x_{0}, U, W\right)\right) p(W)
$$

Aggregation of all the harm values from all the possible scenarios is apparent in the last two equations.

Then, one can form vulnerability indicators by using $V_{H}^{E}$ along with the harm functions defined in Section 2.3.3. For instance, Sandoval-Solis et al. (2011) defines water resources vulnerability indicators as the expected value of $H_{S}, H_{\theta}$ and $H_{\max }$. In particular, a classical indicator is the expected value of the sum of single-stage harms defined as $H_{S}$ in equation (4):

$$
V_{H_{S}}^{E}\left(x_{0}, U\right)=E\left[\sum_{t=0}^{T} h(t, x(t))\right]
$$

In fact, $V_{H_{S}}^{E}$ can be thought of as a total expected cost over $[0, T]$, and is to be called expected cost henceforth.

\subsubsection{Vulnerability as the potential crossing of a threshold}

Vulnerability may be defined as the probability for harm to cross a threshold $\xi$. This constitutes a second family of indicators, which describe the probability of being harmed since they distinguish between "harmed" and comparatively "unharmed" trajectories, a binary classification used to define vulnerability in several studies (e.g. Mendoza et al., 1997; Rockström et al., 2012; Kasprzyk et al., 2013). Such indicators $V_{H}^{\xi}$ are defined by:

$$
V_{H}^{\xi}\left(x_{0}, U\right)=\mathbb{P}\left[H\left(X\left(x_{0}, U, W\right)\right)>\xi\right]
$$

As for expected vulnerability, the probability of being harmed may be derived from any harm function. An oft-encountered indicator is obtained using $V_{H}^{\xi}$ and the binary harm function $H_{\theta}$ (equation (5)). Since $H_{\theta}$ is either 0 or 1 , by taking $\xi=0$ this indicator $V_{H_{\theta}}^{0}$ expresses the probability that single-stage 
harm is 1 . This corresponds to the probability for single-stage harm to cross a threshold value $\theta$ :

$$
\begin{aligned}
V_{H_{\theta}}^{0}\left(x_{0}, U\right) & =\mathbb{P}\left[H_{\theta}\left(X\left(x_{0}, U, W\right)\right)=1\right] \\
& =\mathbb{P}\left[\exists t \in[0, T], x(t) \notin K_{\theta}(t)\right]
\end{aligned}
$$

The latter arguably constitutes an important subfamily of vulnerability indicators on its own; for instance, vulnerability as the probability for a system to evolve into a less desirable state has been used in the context of social-ecological systems (e.g. Peterson, 2002). Indeed, vulnerability can be defined in development economics as the probability now that a relevant quantity - e.g., wealth, food supply be lower (greater) than a maximal (minimal) threshold in the future (e.g. Christiaensen and Boisvert, 2000; Hoddinott and Quisumbing, 2003; McCulloch and Calandrino, 2003). A function of the gap or distance between the measured quantity and the threshold then provides additional poverty measures (Foster et al., 1984), or, if one is looking at expected value of this function in the future, additional vulnerability measures (Christiaensen and Boisvert, 2000; Hoddinott and Quisumbing, 2003).

\subsubsection{Worst-case approach to vulnerability}

Another approach to vulnerability is to consider the worst-case scenario, and vulnerability may then be expressed as the maximal value of harm over $\Omega^{3}$ :

$$
V_{H}^{\max }\left(x_{0}, U\right)=\max _{W \in \Omega}\left\{H\left(X\left(x_{0}, U, W\right)\right)\right\}
$$

Yet, the latter value often corresponds to what might happen in the event of the worst cataclysm, and therefore may not be relevant because the outcome might then be catastrophic no matter $x_{0}$ and $U$. Thus, it may be more relevant to express vulnerability through high quantiles of the distribution of harm values. This can be equated with finding the critical harm value that is not exceeded with a confidence level $\beta$ such as $90 \%, 95 \%, 99 \%$ or even higher. Let us call critical harm this family of vulnerability indicators, and note it $V_{H}^{\beta}$ :

$$
V_{H}^{\beta}\left(x_{0}, U\right)=\min \left\{z \in \mathbb{R}^{+}, \mathbb{P}\left[H\left(X\left(x_{0}, U, W\right)\right) \leq z\right] \geq \beta\right\}
$$

In particular for $\beta=1$, the only harm value that has a $100 \%$ chance of not being exceeded is that of the worst-case scenario, so that $V_{H}^{\max }\left(x_{0}, U\right)=V_{H}^{1}\left(x_{0}, U\right)$. For instance, Loucks (1997) proposes vulnerability indicators by applying the above formula for $V_{H}^{\beta}$ along with harm functions $H_{S}$ and $H_{\max }$.

\subsection{Policy design and vulnerability reduction}

\subsubsection{Minimizing vulnerability}

Let us now make a link between vulnerability and the design of policies that may be devised in order to reduce or avoid it. A straightforward way to reduce vulnerability is to find a policy that minimizes it, when this is possible. Then, for a given vulnerability indicator $V_{H}$, we search for a policy $U^{*}$ that minimizes $V_{H}\left(x_{0}, U\right)$ for a given initial state $x_{0}$. When such a policy exists, minimal vulnerability,

\footnotetext{
${ }^{3}$ In practice, the maximum is often taken over a representative subset $\bar{\Omega}$ of $\Omega$, e.g., through discretization
} 
noted $V_{H}^{*}$, may be expressed as a function of the initial state alone:

$$
V_{H}^{*}\left(x_{0}\right)=V_{H}\left(x_{0}, U^{*}\right)=\min _{U \in U_{a}(T)}\left\{V_{H}\left(x_{0}, U\right)\right\}
$$

\subsubsection{Examples of vulnerability minimization}

This paragraph presents cases of vulnerability indicators $V_{H}$ for which stochastic dynamic programming (SDP) is a way to find a policy $U^{*}$. SDP is an algorithm that recursively computes both the minimal value of vulnerability from stage $t$ to stage $T$, and a policy which leads to that minimal value. It does so by progressing backward from the final stage to the initial one. SDP needs the assumption, made from now on, that for any couple of different dates $t_{1}$ and $t_{2}$, the random vectors $w\left(t_{1}\right)$ and $w\left(t_{2}\right)$ are statistically independent from each other. There exist a number of methods other than SDP that may be more appropriate to specific situations. Yet, SDP in particular is mentioned in this work for its ability to find policies that minimize vulnerability for different types of common indicators, namely the expected cost $V_{H_{S}}^{E}$ defined by equation (11), and the probability of crossing a threshold of single-stage harm, $V_{H_{\theta}}^{0}$ (equation (14)).

In the former case, minimizing the expected cost $V_{H_{S}}^{E}$ using SDP amounts to a classical example of cost minimization (e.g. Loucks and van Beek, 2005; De Lara and Doyen, 2008). Then for an initial state $x_{0}$, using equation (17) leads to the definition of the minimal expected $\operatorname{cost} V_{H_{S}}^{E *}\left(x_{0}\right)$.

In the latter case, the probability of crossing a threshold of single-stage harm can equally be expressed using the probability of not crossing that threshold:

$$
V_{H_{\theta}}^{0}\left(x_{0}, U\right)=1-\mathbb{P}\left[\forall t \in[0, T], x(t) \in K_{\theta}(t)\right]
$$

Vulnerability is minimized when the latter probability is maximized. Maximizing the probability of staying in a constraint set at each and every stage is a goal of a branch of control theory, namely stochastic viability theory (De Lara and Doyen, 2008). This theory was used to design sustainable policies under uncertainty in social-ecological systems such as fisheries (Doyen and Béné, 2003; De Lara and Martinet, 2009; Doyen et al., 2012) or grassland agro-ecosystems (Sabatier et al., 2010). Doyen and De Lara (2010) link stochastic viability with SDP, by proposing a SDP algorithm that finds a policy $U^{*}$ that maximizes the probability of keeping the properties of a system (see Appendix B for details). Then, $U^{*}$ also minimizes $V_{H_{\theta}}^{0}$. According to equation (17), this leads to the definition of the function $V_{H_{\theta}}^{0 *}\left(x_{0}\right)$ which gives the minimal probability of crossing the single-stage harm threshold $\theta$ at the initial state $x_{0}$.

\subsubsection{Other ways of selecting appropriate policies}

The search for an optimal policy is often difficult or even impossible, because one does not know enough about the system to compute it analytically. This is why Ionescu et al. (2009) contend that a more general way of deriving appropriate policies is by finding some of those that keep vulnerability below a reference level. We distinguish between two ways of defining that reference level. In both cases, once a satisfactory or an adaptive policy $U$ has been selected, vulnerability only depends on the initial state $x_{0}$. Note that $U$ can be different for different values of $x_{0}$. 
On one hand, the reference level can be defined as a vulnerability threshold $v$ that stakeholders would rather not exceed. Then, for $x_{0}$ a policy $U$ is satisfactory - or acceptable - if:

$$
V\left(x_{0}, U\right) \leq v
$$

This notion of acceptability leads to also labeling policies as either acceptable or not. On the other hand, the reference level can be defined for a given initial state $x_{0}$ by a reference or baseline policy $U_{0}$. Then according to equation (19), we have $v=V\left(x_{0}, U_{0}\right)$, and the goal is then to find alternative policies that lower vulnerability, e.g. among a set of predefined policy options. A policy that succeeds in lowering vulnerability may be called adaptive (Luers et al., 2003), and one that increases it may then be called maladaptive (Burton, 1997; Smit et al., 2000).

\section{Application}

\subsection{A simple lake eutrophication problem}

We illustrate the proposed framework with the discrete-time lake eutrophication model by Carpenter et al. (1999) (C99 thereafter). In what follows, the state at stage $t$ is $x(t)=(P(t), L(t))$, and it is assumed that each stage represents a year. $P(t)$ is the phosphorus $(\mathrm{Ph})$ concentration in the lake at the end of year $t$, and $L(t)$ is the excess $\mathrm{Ph}$ from human activities during year $t$. All variables are dimensionless, and the discrete-time evolution of the state reads:

$$
\left\{\begin{array}{l}
P(t+1)=P(t)+[L(t)+u(t)] e^{w(t)}-b P(t)+\frac{P(t)^{q}}{1+P(t)^{q}} \\
L(t+1)=L(t)+u(t)
\end{array}\right.
$$

Equation (20) corresponds to the case from C99 with stochastic inputs. The control is $u(t)$, and choosing its value amounts to a new decision on state $L(t)$. Decisions concerning phosphorus use in human activities may only be made every $Y$ years, so as to represent inertia in decision-making (e.g., institutional inertia). Then, any value can be chosen between 0 and $L_{\max }$ which represents the value of $L$ beyond which farmers and other $\mathrm{Ph}$ users no longer have an incentive for using more $\mathrm{Ph}$ in agriculture. Formally speaking, this amounts to choosing the set of available controls $U_{a}(t, L)$ as follows:

$$
U_{a}(t, L)= \begin{cases}{\left[-L, L_{\max }-L\right]} & \text { if } \exists k \in \mathbb{N}, t=k . Y \\ \{0\} & \text { otherwise }\end{cases}
$$

Uncertainty is represented by $w(t)$. Thus, equation (20) corresponds to the formulation $x(t+1)=$ $f(t, x(t), u(t), w(t))$ from equation (1). Ph input into the lake is $L(t) e^{w(t)}$; it is stochastic because the soil stores $\mathrm{Ph}$ and acts as a buffer. $w(t)$ is a realization of a random variable with Student distribution, with standard deviation $\sigma_{d}$ and $d f$ degrees of freedom (dof); the pdf of $w\left(t_{1}\right)$ and $w\left(t_{2}\right)$ at any two stages $t_{1}$ and $t_{2}$ are independent and identically distributed. The parameter $b$ determines how fast $\mathrm{Ph}$ is eliminated in from the lake, for example as outflow.

In what follows, we set $T=100$, and assess vulnerability from harm over the future period $[1, T]$. Parameter values are from Figures 11, 12 and 14 from C99, and are summarized in Table 2; the interval 


\begin{tabular}{c|c|c} 
Notation & Description & Value or interval \\
\hline$P$ & Ph concentration & {$[0,2]$} \\
$L$ & Excess Ph & {$[0,0.15]$} \\
$b$ & lake parameter & 0.55 \\
$q$ & lake parameter & 2 \\
$Y$ & lag in decision-making & 10 \\
$d f$ & dof of $w(t)$ & 10 \\
$\sigma_{d}$ & standard deviation of $w(t)$ & 0.25
\end{tabular}

Table 2: Summary of the parameters for the baseline case of Section 3.

for $P$ is chosen so all $\mathrm{Ph}$ dynamics are represented. $P$ and $L$ are discretized over a grid, with resolutions $\Delta P=0.01$ and $\Delta L=0.001$.

$\mathrm{Ph}$ has been proved to be the main inducer of lake eutrophication (Schindler, 2006; Schindler et al., 2008). A clear-water lake is called oligotrophic, and it generally has high-quality water as well as a healthy ecosystem. Eutrophication lowers the value of ecosystem services from a lake, impairing water quality as well as activities such as fishing or recreation. Therefore, Ph inputs must be controlled to avoid ecological degradation of lakes (Carpenter, 2008). A lake must be managed to balance $\mathrm{Ph}-$ producing economic activities with its ecological preservation. These trade-offs are made explicit through harm functions.

\subsection{Trade-offs in harm evaluation}

In the model from C99, harm is associated with 1) being limited in the quantity of $\mathrm{Ph}$ that can be used for economic activities and 2) the presence of $\mathrm{Ph}$ in the lake. We choose to reuse the quadratic utility functions from Equations (4) and (5) from C99, since 1) quadratic utility functions are simple examples of concave utility functions, and 2) single-stage harm functions can be seen as the opposite of (single-stage) utility functions. However, compared to C99, we use different numerical coefficients when expressing ecological harm $h_{e l}(P)$ and economic harm $h_{e n}(L)$ :

$$
\begin{array}{r}
h_{e l}(P)=P^{2} \\
h_{e n}(L)=\frac{4}{L_{\max }}\left(L_{\max }-L\right)^{2}
\end{array}
$$

Then, single-stage harm $h(t, x)$ is stationary, so that it is more simply noted $h(x)$, and it is expressed as the weighted sum of ecological harm $h_{e l}(P)$ and economic harm $h_{e n}(L)$ :

$$
h(x)=\lambda h_{e l}(P)+(1-\lambda) h_{e n}(L)
$$

where $\lambda$, comprised between 0 and 1 , weighs ecological harm with respect to economic harm; it is a means to explore potential trade-offs between both sources of harm, and if and how their relative importance affects decision-making. Coefficients in equations (22) and (23) have been adjusted from C99 so as to set both quadratic harm functions $h_{e l}$ and $h_{e n}$ on an equal footing, which facilitates the analysis of trade-offs between vulnerability sources. This is why $h_{e l}$ and $h_{e n}$ have comparable shape weights: they range from 0 to 4 over the respective intervals for $P$ and $L$.

Once single-stage harm has been defined, it is used to compute harm over the lake's possible 
trajectories $X$. This application focuses on two of the ways proposed in Section 2.3 to aggregate single-stage harm values over a horizon. On one hand, it uses total cost $H_{S}(X)$ defined in equation (4), the sum of single-stage costs. On the other hand, harm is assessed as the fact of leaving a region defined by a single-stage harm threshold $h(x)=1$. With the conventions from equations (6) and (5) respectively, we define the constraint set $K_{1}$ thanks to this threshold, then the binary harm function $H_{1}(X)$ which value is 1 if the threshold is crossed at some point during the trajectory, and 0 otherwise.

Figure 2 provides a first illustration of the consequences of the choice of the weight $\lambda$ balancing ecological and economic harm. Choosing $\lambda$ naturally affects single-stage harm for each state but beyond that, $\lambda$ alongside the dynamics determine which policy choices are made. For a given value of $L, P$ converges towards a stable attractor, such attractors being represented by the continuous lines. The continuous line for which $\mathrm{Ph}$ concentration is low corresponds to an oligotrophic lake, whereas the line for which it is high corresponds to a eutrophic lake. The existence of two stable attractors for some values of $L$ makes eutrophication difficult to reverse. Indeed, there can be an oligotrophic lake for $L=0.07$ for instance, but if for some reason the system were to tip towards a eutrophic state, then $L$ would have to be lowered below 0.05 for some time to recover the lake's ecological health, hurting the economy in the process.

In case $(a)$ where $\lambda=0.5$, attractors with lowest single-stage harm are with moderate values of $L$ and low values of $P$. They are also the only attractor in the constraint set. Therefore, trajectories $X$ that remain around these attractors would fare well when evaluated both by the total harm function $H_{S}(X)$ and the binary harm function $H_{1}(X)$. Even though it also takes into account economic interest, $\lambda=0.5$ promotes policies that keep the lake oligotrophic. By contrast, case $(b)$ where $\lambda=0.2$ puts a much heavier weight on the economy, and it is a choice that corresponds to policies promoting a high level of $\mathrm{Ph}$ emissions. These policies lead to eutrophication, yet corresponding trajectories have good performance when evaluated by both $H_{S}$ and $H_{1}$.

\subsection{Vulnerability analysis of lake eutrophication}

Figure 2 only provides a rule of thumb about the policies that may be implemented to reflect the choice of $\lambda$. Vulnerability indicators enable a quantitative evaluation of the impact of different parameters, and they take into account how the uncertain dynamics may affect the system's trajectory. Since a control is chosen to determine $L(1)$ independently of the initial value $L_{0}$, vulnerability only depends on initial phosphorus concentration $P_{0}$ and on the chosen policy.

The remainder of Section 3 is to evaluate the impact of the weight $\lambda$ on both enacted policies and the resulting vulnerability. The range for $\lambda$ is from 0 to 1 ; it is explored with a resolution of 0.05 . For a given value of $\lambda$, two types of vulnerability indicators are being used. On one hand, $V_{H_{S}}^{E}\left(P_{0}, U\right)$ defined in equation (11) is the expected value of the cost function $H_{S}(X)$ along lake trajectory $X$. We also define ecological and economic vulnerability, respectively, as the expected value of the sum of single-stage ecological and economic harm along a trajectory. Noting $V_{e l}\left(P_{0}, U\right)$ ecological vulnerability 
(a) Static harm $h(x)$ for $\lambda=0.5$

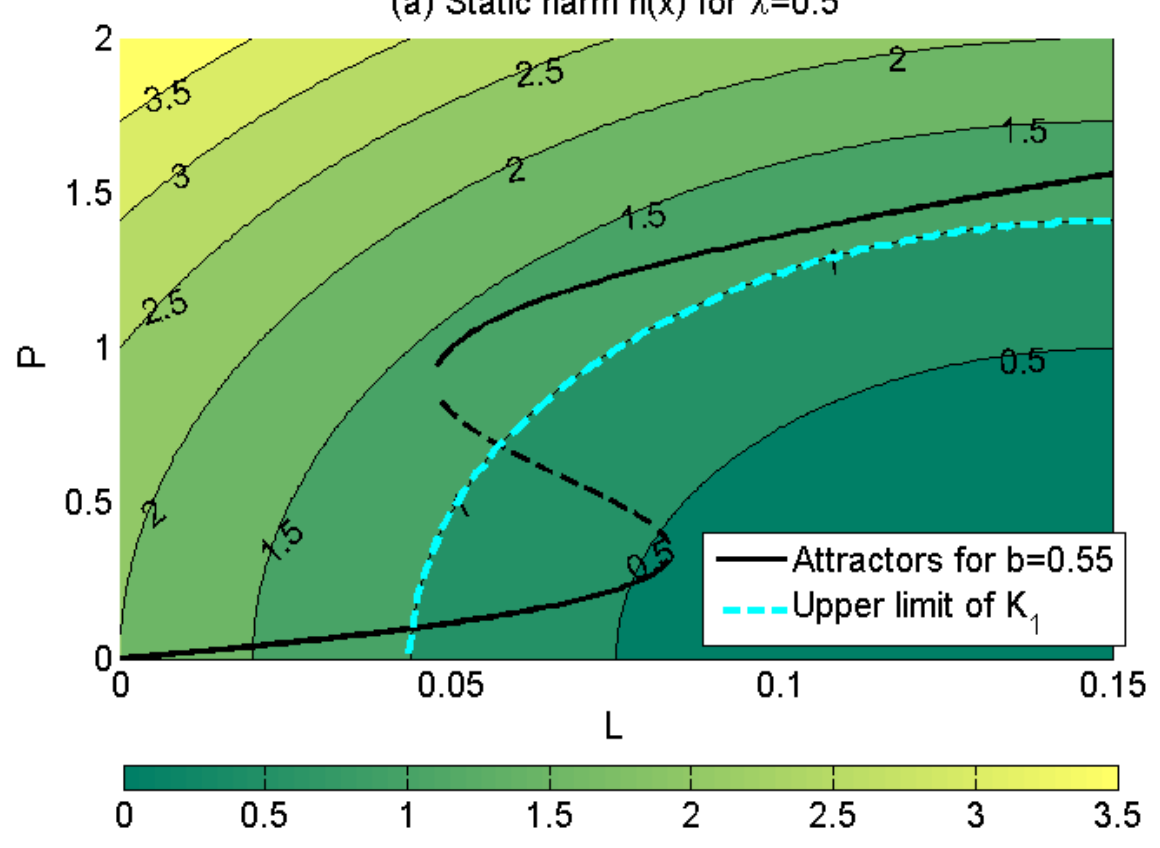

(b) Static harm $\mathrm{h}(\mathrm{x})$ for $\lambda=0.2$

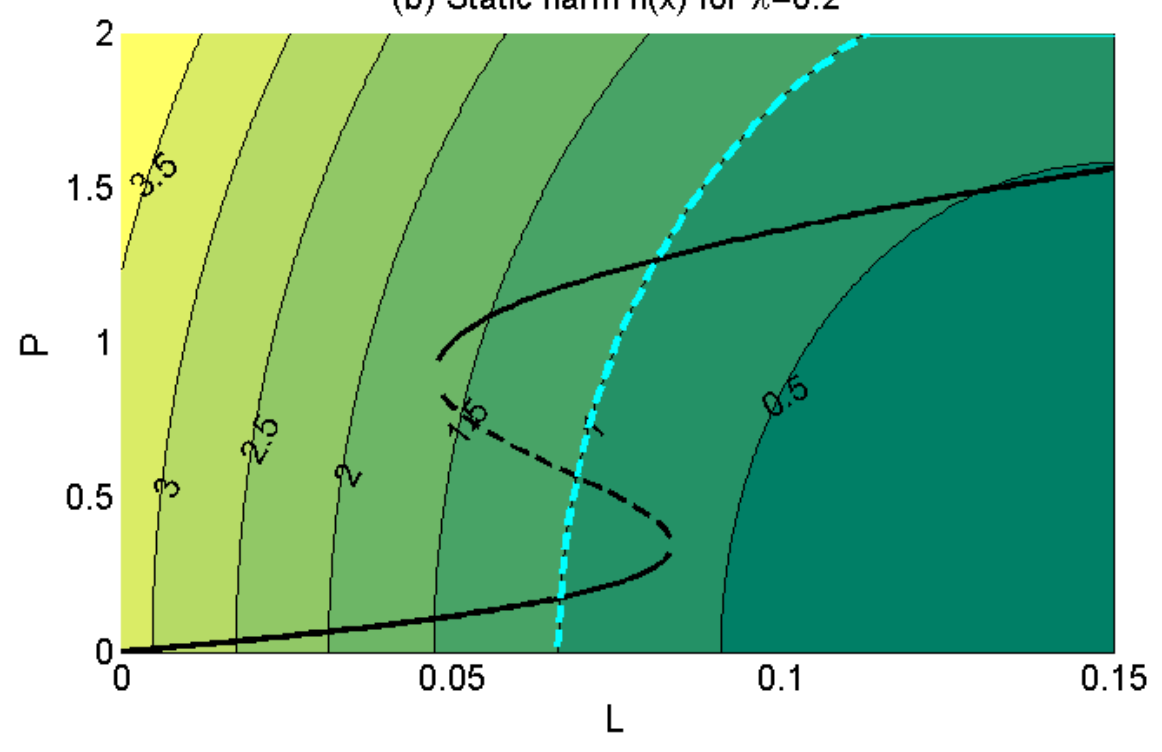

Figure 2: Single-stage harm for $(a) \lambda=0.5$ and $(b), \lambda=0.2$. The set $K_{1}$ and attractors of the dynamic for $b=0.55$ are also represented. The continuous lines are stable attractors while the dotted line represents the unstable ones. 
and $V_{e n}\left(P_{0}, U\right)$ its economic counterpart yields:

$$
\begin{aligned}
V_{e l}\left(P_{0}, U\right) & =E\left[\sum_{t=1}^{100} h_{e l}(P)\right] \\
V_{e n}\left(P_{0}, U\right) & =E\left[\sum_{t=1}^{100} h_{e n}(L)\right]
\end{aligned}
$$

$V_{e l}$ and $V_{e n}$ are vulnerability indicators because they respectively aggregate single-stage ecological and economic harm, first over whole time frame $[0, T]$, then over all possible scenarios. $V_{H_{S}}^{E}\left(P_{0}, U\right)$ is the sum of both indicators:

$$
V_{H_{S}}^{E}\left(P_{0}, U\right)=V_{e l}\left(P_{0}, U\right)+V_{e n}\left(P_{0}, U\right)
$$

As indicated in Section 2.5.2, the vulnerability-minimizing policy is found by SDP. We will note $U_{c}^{*}$ the policy that minimizes expected cost $V_{H_{S}}^{E}\left(P_{0}, U\right)$. That optimal policy is determined by the successive decisions about $L(t)$ depending on $P(t)$ at stages when decisions are taken, and it is dependent on the chosen value of $\lambda$ (Figure 3.a). There are two types of optimal decisions. For low values of $\lambda$, heavy emphasis on limiting economic vulnerability leads to decisions which enable high $\mathrm{Ph}$ inputs into the lake no matter the value of $P$. As a consequence, economic vulnerability is low while ecological vulnerability is close to maximal (Figure 3.b). To the contrary, for values of $\lambda \geq 0.4$ decisions prioritize the ecological integrity of the lake, and only permit Ph-producing activities as long as that integrity is not threatened. This leads to high economic vulnerability but low ecological vulnerability - and since eutrophication is difficult to reverse, initial $\mathrm{Ph}$ concentration $P_{0}$ has an influence on vulnerability. $\lambda=0.35$ is a critical value, for which the current (initial) state of the lake determines future decisions. This trade-off between ecological and economic vulnerabilities $V_{e l}$ and $V_{e n}$ is inescapable since Figure 3.b features a Pareto front, which means that for the values of $P_{0}$, it is impossible to reduce both $V_{e l}$ and $V_{e n}$ below any of the values given by the fronts.

On the other hand, this application uses $V_{H_{1}}^{0}\left(P_{0}, U\right)$ defined by equation (14), which is the probability of crossing the threshold of harm $h(P(t), L(t))=1$. Again, SDP yields the minimal probability of crossing that threshold, and $U_{\tau}^{*}$ is a corresponding policy. Its effects can be compared to that of policy $U_{c}^{*}$ yielding the minimal expected cost (Figure 4). As expected, $U_{\tau}^{*}$ outperforms $U_{c}^{*}$ with respect to vulnerability indicator $V_{H_{1}}^{0}\left(P_{0}, U\right)$ (Figure 4.a). Conversely, $U_{c}^{*}$ outperforms $U_{\tau}^{*}$ with respect to vulnerability indicator $V_{H_{S}}^{E}\left(P_{0}, U\right)$ (Figure 4.b): there is a trade-off between respecting the singlestage harm threshold of 1 , and minimizing the expected cost. For both indicators and both policies, a lower vulnerability is obtained by conveniently forgoing either ecological ( $\lambda$ close to 0 ) or economic ( $\lambda$ close to 1 ) vulnerability, than by finding compromise policies that take both vulnerability sources into account. For a given value of $\lambda, U_{\tau}^{*}$ tends to lead to the implementation of more ecologically conservative policies than $U_{c}^{*}$, because such policies lower the risk that exceptional values of $w(t)$ cause the $\mathrm{Ph}$ dynamics to drive the system through the threshold $h(t, x)=1$. They yield high values of the expected cost $V_{H_{S}}^{E}\left(P_{0}, U\right)$ because economic vulnerability is very high, so that trade-offs are between respecting the single-stage harm threshold of 1 , and economic vulnerability. 

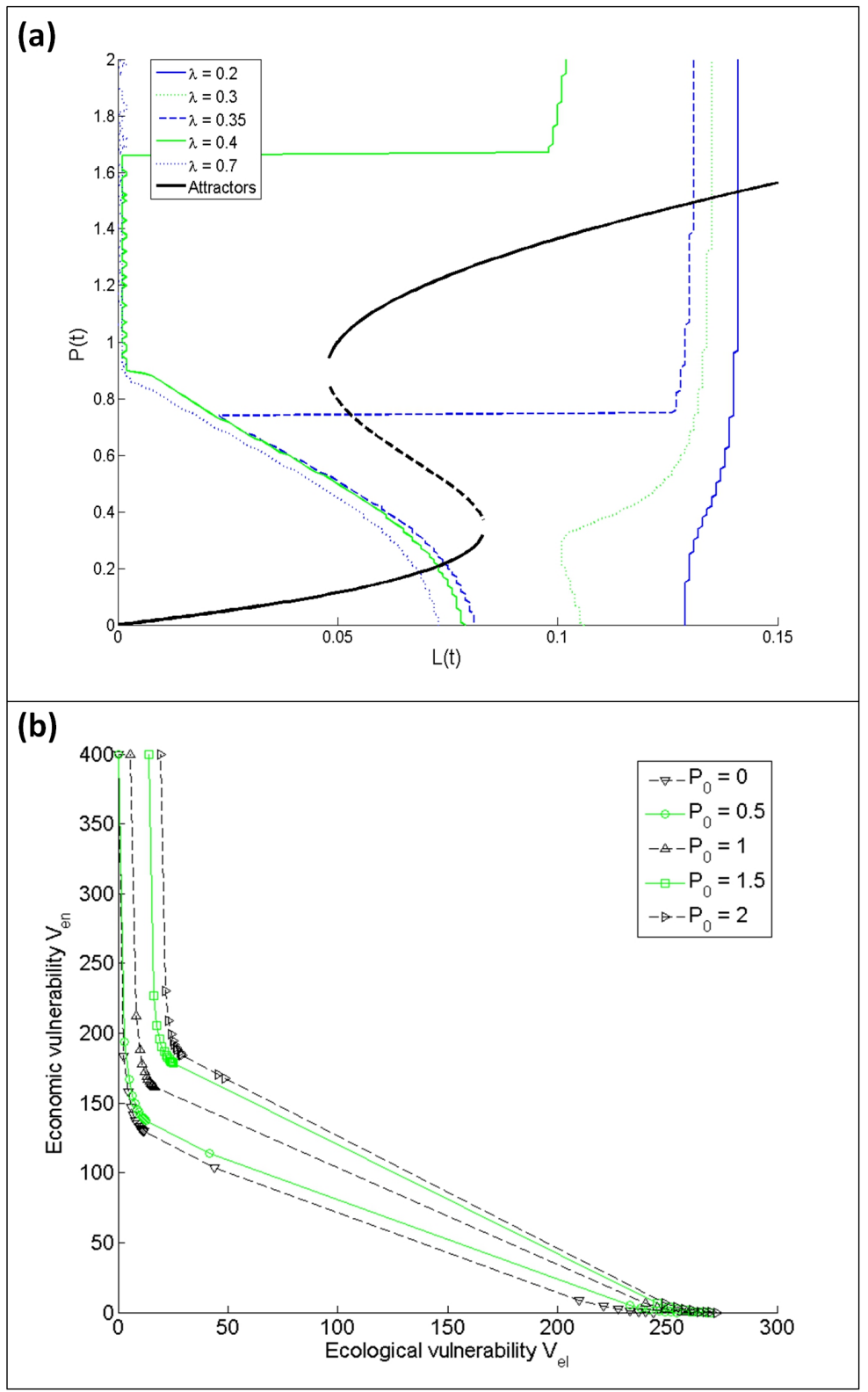

Figure 3: For different values of $\lambda$ in the base case $b=0.55, Y=10$, and vulnerability indicator $V_{H_{S}}^{E}\left(P_{0}, U_{c}^{*}\right)$. (a) Decisions (choices of $L(t)$ as a function of $P(t)$ every $Y$ years) optimally reflecting preferences and $(b)$ Pareto front of ecological vs. economic vulnerability for different values of $P_{0}$. 
(a)

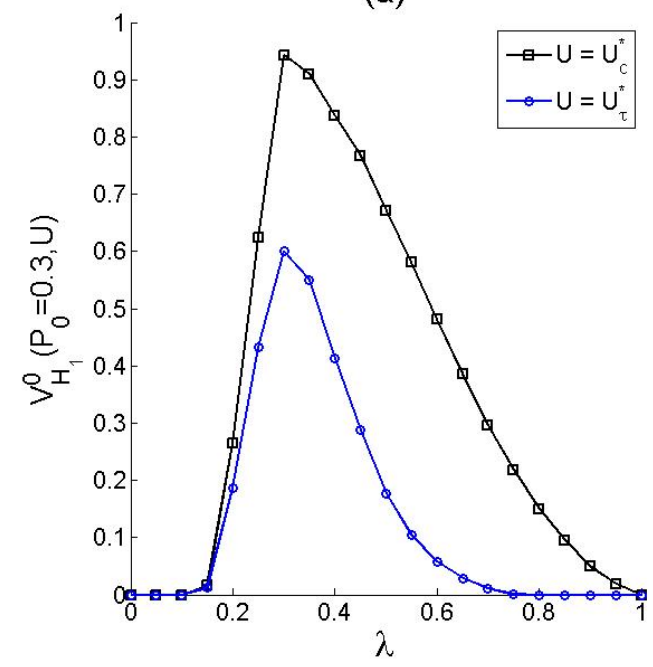

(b)

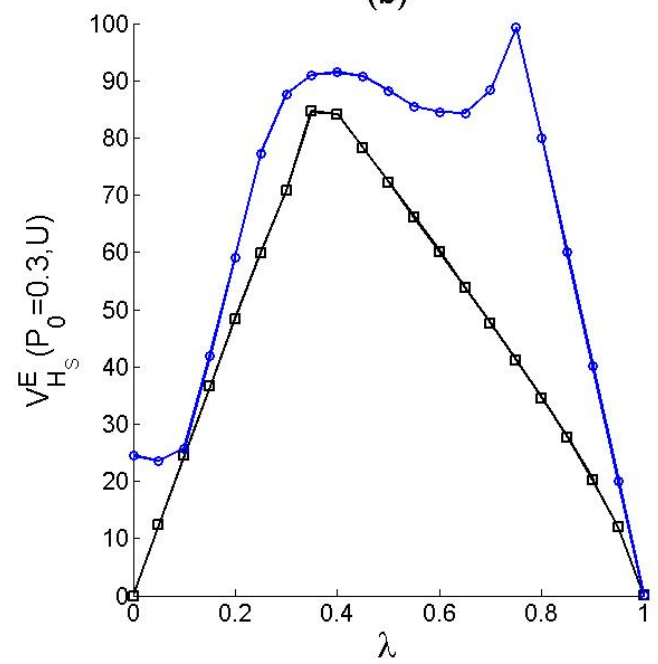

Figure 4: Comparison of policies $U_{c}^{*}$ and $U_{\tau}^{*}$ depending on $\lambda$ for $P_{0}=0.3$, regarding their effects on (a) the probability $V_{H_{1}}^{0}\left(P_{0}, U\right)$ of crossing the harm threshold $K_{1}$, and (b) the expected cost $V_{H_{S}}^{E}\left(P_{0}, U\right)$.

\subsection{Change in the lag $Y$ between two controls}

A reduction of the lag $Y$ between two controls may reflect improved system monitoring and governance. It is expected to enable the implementation of better optimal policies with respect to a given indicator. Figure 5 shows how the optimal policy for the total expected cost $V_{H_{S}}^{E}\left(P_{0}, U\right)$ is impacted by this reduction at $P_{0}=1$. The total cost is only reduced $\lambda=0.4$ and above, a range where policy decisions prioritize keeping the lake in a clear water state. In that range, the greater part of vulnerability is economic (Figure 3), so that vulnerability reductions essentially correspond to reductions in economic vulnerability. Therefore, when policies prioritize lake conservation, $\mathrm{Ph}$ consumers that reject excess $\mathrm{Ph}$ into the lake benefit from more reactive policy-making. Conversely, if policies prioritize economic interests at the expense of lake ecology, more reactive policy-making is inconsequential for $V_{H_{S}}^{E}\left(P_{0}, U\right)$, and the variations in economic vulnerability $V_{e n}$ observed for $\lambda<0.4$ are insignificant, because $V_{e n}$ is close to 0 .

\subsection{Change in $\mathrm{Ph}$ outflow parameter $b$}

Global change can potentially affect a lake in a number of ways (e.g. Beklioglu et al., 2007; Schindler et al., 2008; Jeppesen et al., 2009). This section focuses on the impacts of possible modifications of the rainfall regime. Lower precipitation may affect the outflow from the lake, which lowers $\mathrm{Ph}$ outflow $b$, but also the $\mathrm{Ph}$ inputs if it is accompanied of rainfall events of lower intensity (Schindler et al., 2008). However, $\mathrm{Ph}$ is disproportionately released from the soil into the lake by important runoff events (Sharpley et al., 2008; Rodríguez-Blanco et al., 2013), and more extreme precipitation is expected (Jeppesen et al., 2009), so that more extreme events may balance the lower quantity of total precipitation when it comes to releasing $\mathrm{Ph}$ into the lake. As a result, we simply explore the consequences of a shift in $b$, namely a $10 \%$ decrease. Therefore, the rest of this section asssumes 


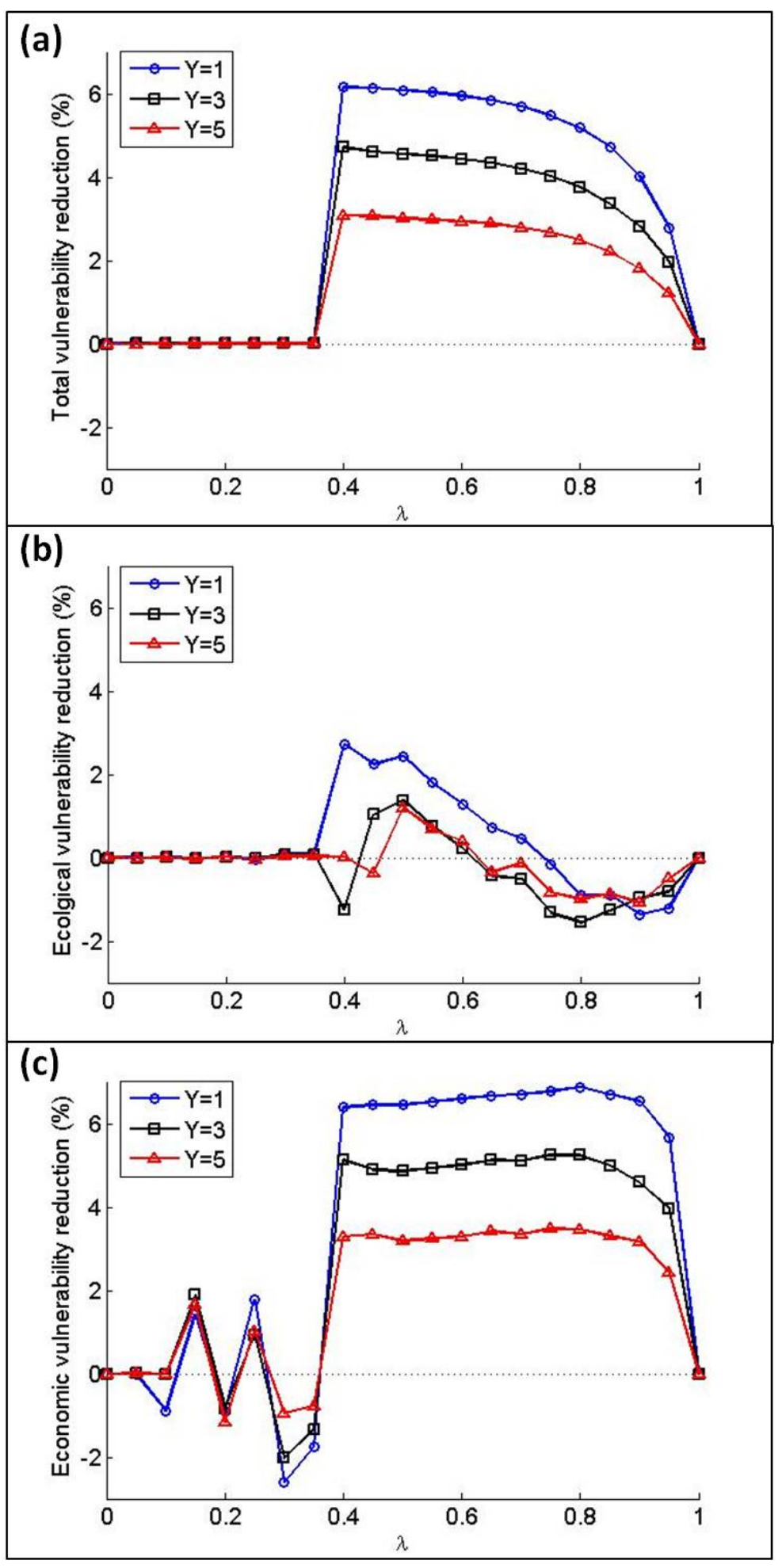

Figure 5: Percentage of vulnerability reduction by reducing the lag $Y$ between two controls, from $Y=$ 10. For $P_{0}=1(a)$ total vulnerability, $(b)$ ecological vulnerability only and $(c)$ economic vulnerability only. 

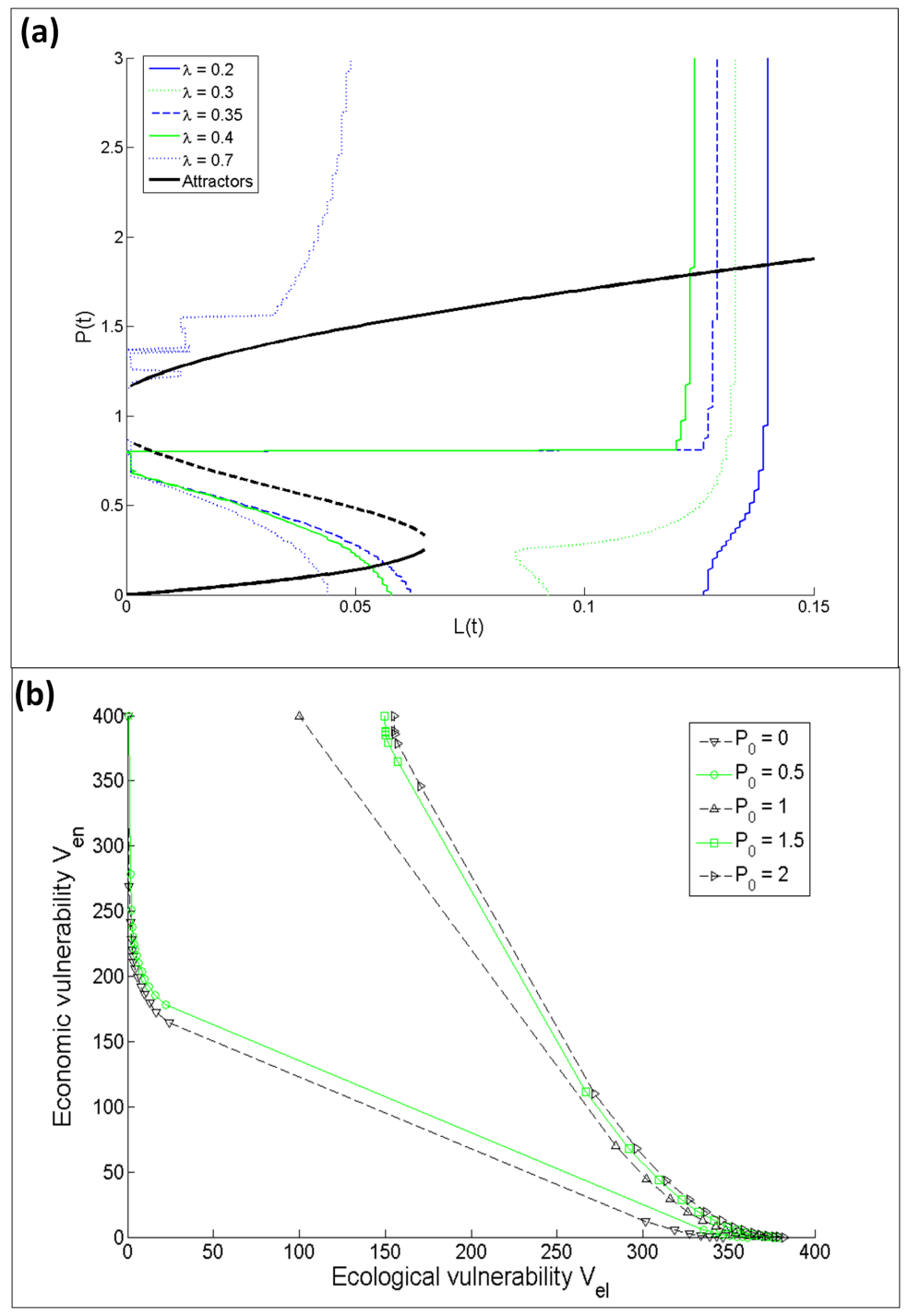

Figure 6: Same as Figure 3 but with Ph lake outflow $b=0.495$.

$b=0.495$. All else is the same as in Section 3.3 and in particular, the lag $Y$ is 10 .

With $b=0.495$, attractors change and eutrophication is now irreversible (Figure 6.a). Indeed, there is no value of $L(t)$ for which the only attractor has a low $\mathrm{Ph}$ concentration, therefore the lake is poised to remain close to a eutrophic attractor after it gets near one. As a result, there are two types of decisions in Figure 6.a. For a low value of $\lambda(<0.3)$, preference for economic outcomes leads to decisions that make the lake eutrophic. This is similar to the baseline case $b=0.55$, with the exception that this decision now becomes irreversible. For $\lambda=0.35$ and higher, decisions aim at keeping the lake in a clear-water state as long as this is possible; otherwise, they choose a eutrophic attractor that reflects the choice of $\lambda$. The higher $\lambda$, the higher the priority on the lake's ecological health, and the more cautious the chosen policy for low values of $P(t)$.

Practical consequences of irreversible eutrophication also translates into trade-offs between ecolog- 


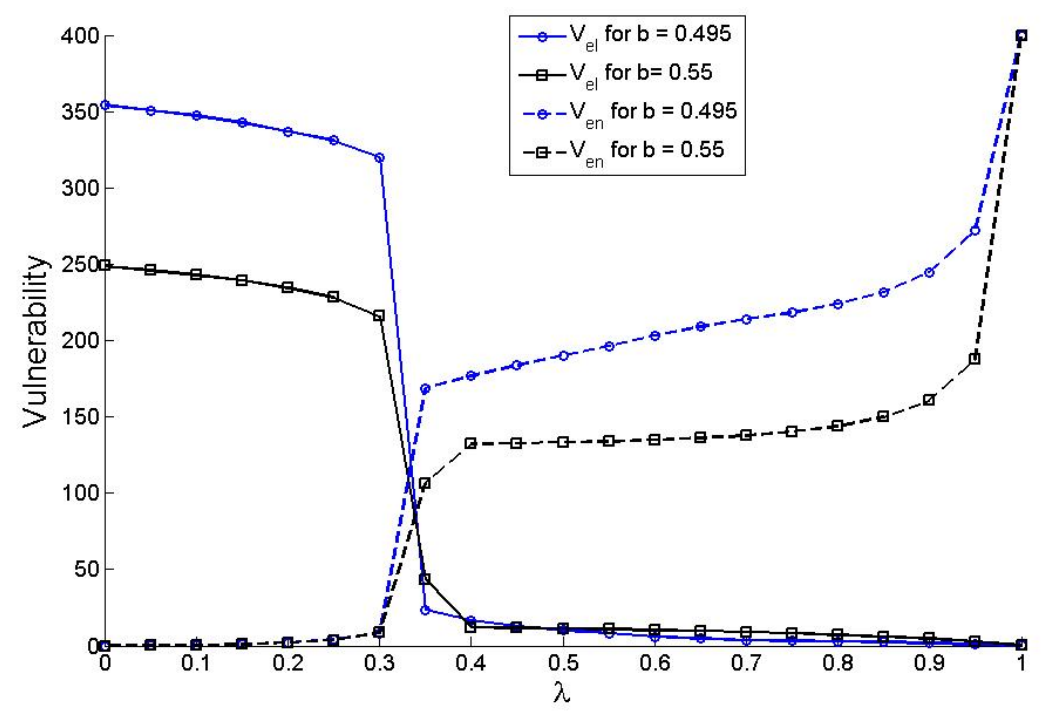

Figure 7: Comparison of ecological vulnerability $V_{e l}$ and economic vulnerability $V_{e n}$ with $b=0.55$ and $b=0.495$, under the optimal policy $U_{c}^{*}$ for the indicator $V_{H_{S}}^{E}\left(P_{0}, U\right)$. For $P_{0}=0.3$, and different values of $\lambda$.

ical and economic vulnerability that are different for $b=0.55$ (Figure 3.b) and $b=0.495$ (Figure 6.b). While in the former case, there was only a quantitative dependence of the Pareto Front on the initial $\mathrm{Ph}$ concentration $P_{0}$, in the latter case, there is a qualitative difference for high values of $P_{0}$. Since the lake is then bound to become and stay eutrophic, there is no policy guaranteeing low ecological vulnerability.

One can also assess the consequences of $b=0.495$ in comparison with $b=0.55$, for instance for $P_{0}=0.3$ (Figure 7). Then for $b=0.495$, ecological vulnerability $V_{e l}$ and economic vulnerability $V_{e n}$ can be decomposed into two entities. On one hand, there is vulnerability with $b=0.55$, which corresponds to vulnerability before the change in $b$ occurs. On the other hand, additional vulnerability can be interpreted as vulnerability to the change in $b$. Thus, vulnerability to a specific event may be computed by comparing the value of a vulnerability indicator before and after that event.

\section{Discussion}

The proposed formal framework for vulnerability is meant to accommodate a wide range of field- or case-specific definitions, since it relies on the largest possible definition of the term as a measure of possible future harm. It uses a discrete-time stochastic controlled dynamical system representation which is well-suited to the definition of vulnerability and related concepts through successive abstraction. Starting from one-step discrete-time dynamics, a first abstraction through aggregation over a period $[0, T]$ leads to the definition of harm over a trajectory. Then, a second abstraction aggregates harm values over all trajectories into vulnerability indicators. Finally, a third abstraction consists in choosing a policy that is appropriate in the sense that it minimizes or limits the chosen vulnerability indicator. Examples show how the framework applies to a variety of indicators, as also illustrated 
by simple case of lake eutrophication. This application also showcases how this framework is also appropriate to discuss the trade-offs that may exist between sources of vulnerability in many systems. The remainder of this section is to discuss how the proposed formalization relates to various topics encountered in the literature and related to the concept of vulnerability.

The proposed perspective assumes that the probability distribution of the scenarios $W$ is known. In reality, major hazard events are by definition extreme and rare, so that the estimation of their return period can be very uncertain and heavily dependent on the pdf used to approximate them (Esteves, 2013); and it has been shown that providing such estimates is far more perilous in the context of a changing climate (Felici et al., 2007a,b). In general, many authors acknowledge that the probability of occurrence of some hazards cannot be quantified, and they then qualify as unknown unknowns (Swanson et al., 2010; Beck and Kropp, 2011), "uncertainty and surprise" (Folke et al., 2002, 2004; Adger et al., 2005), or as uncomputable uncertainty (Carpenter et al., 2008). Similar to Section 3.5, vulnerability to such hazards can be quantified by comparing vulnerability in their presence to vulnerability in their absence. Exploring the consequences from the occurrence of extreme events then falls under the umbrella of "scenario planning" (Allen et al., 2011; Cobb and Thompson, 2012), because the proposed framework enables assessing vulnerability to events defined by such "scenarios".

The application to lake eutrophication shows how vulnerability indicators can be adept at describing trade-offs between vulnerability sources, e.g., ecological and economic. This relates to the idea that reducing vulnerability to some stressors or shocks in some part of a system may be at the expense of increasing vulnerability to other stressors or other shocks in some other part of the same system. This may seem relatively straightforward when investigating ecological vs. economic vulnerability in the simple case of Section 3, but in some cases the negative impacts of reducing vulnerability to certain well-identified shocks may be felt across different space or time scales (Anderies and Hegmon, 2011; Rodriguez et al., 2011; Schoon et al., 2011). Such effects have been studied under the name of robustness-vulnerability trade-offs, whereby increasing robustness to a set of shocks can increase vulnerability to another set of shocks (Anderies et al., 2007). The idea that reduced vulnerability somewhere in a system often comes at a price is a call for integrated assessment, as it encourages one to understand and assess what this price is before implementing shortsighted policies.

The literature on robustness-vulnerability trade-offs is also related to robust control (Doyle et al., 1990; Zhou and Doyle, 1998) where feedbacks are designed to make a valued property of a system robust to a given set of shocks. Similarly, this paper links vulnerability with another branch of control theory: viability theory (Aubin, 1991; De Lara and Doyen, 2008), which in its stochastic version, also aims at designing adaptive feedback policies to avoid the crossing of a threshold. These links are natural since control theories can relate to policy design, and their use must be kept in mind when defining policyrelevant indicators. Besides, confrontation of vulnerability-related concepts with methods and notions from such theories is promising. For instance, the stochastic viability kernel (Doyen and De Lara, 2010) is the set of initial states such that the probability of crossing a threshold during a given period is below a set number. It has been used in the definition of concepts such as robustness and resilience (Martin, 2004; Deffuant and Gilbert, 2011; Rougé et al., 2013). Some frameworks (e.g. Turner II et al., 2003) rather use the concept of resilience to describe the capacity of a system to cope and adapt. In reality, resilience in its own is a long-standing concept (Holling, 1973), which has given way to a large 
body of literature in many fields (Brand and Jax, 2007). Vulnerability and resilience, due to their distinct disciplinary origins, conceptual center of interests, and methodological approaches, seem to be strongly complementary concepts (Miller et al., 2010).

Besides, this work draws strong connections between vulnerability and economic analyses, beyond the poverty literature cited earlier on. Thus, single-stage harm may in general be defined as the contrary of a utility function, such as in the lake eutrophication case (3.2). Moreover, some indicators given as examples throughout this work have economic interpretations. Expected cost $V_{H_{S}}^{E}$ is self-explanatory in that regard, but the probability $V_{H_{\theta}}^{0}$ of crossing a threshold is related to so-called economic viability analysis (e.g. Doyen et al., 2012), and $V_{H}^{\beta}$ defined by equation (16) defines what is called value-at-risk, a term coming from the economics and finance literature and applied to environmental risk analysis (Webby et al., 2007).

Finally, Sections 2 and 3 show complimentary aspects of the relationship between vulnerability and adaptive capacity. Luers et al. (2003) defines adaptive capacity as the vulnerability reduction caused by a policy change. As suggested by Section 3.4, this change can come from a better choice among available policies, but as illustrated by Section 3.4, it can also spring from a change in the set of available policies - a reduction in the lag in decision-making. In both cases however, the adaptive potential of a policy change can only be evaluated through proper vulnerability indicators. Other frameworks define instead adaptive capacity based on its determinants (Yohe and Tol, 2002), or as the inventory of the resources that can be allocated to adaptation (Nelson et al., 2007; McDowell and Hess, 2012). These evaluation criteria are complimentary, since the former focuses on potential results while the latter emphasizes the causes that make adaptations possible. Additionally, it seems relevant to express adaptive capacity both in terms of absolute vulnerability reduction, but also in terms of relative decrease - similar to Figure 5.

\section{Conclusions and perspectives}

Hinkel (2011) contends that vulnerability indicators are mainly fit for identifying who may be vulnerable and where. A dynamical systems perspective on the matter may transcend this grim diagnosis by fostering the development of fully dynamic indicators that explicitly consider probabilistic outcomes. These indicators can inform and even guide policy choices, so that they truly are at the interface between the representation of social-ecological system and its management. Further, we contend that the vulnerability framework exposed in this paper is helpful regardless of the existence of a dynamical system formulation, for reasons enumerated hereafter.

(1) It ties the definition of vulnerability indicators to the definition of future trajectories within a time frame of interest, as well as that of associated harm values and occurrence probabilities.

(2) It clarifies the descriptive and normative aspects of vulnerability. Even though they come from models whose complete objectivity can inevitably be questioned, trajectories and their associated occurrence probabilities are the descriptive part. Assigning a harm value to a trajectory is the normative part.

(3) In fact, the choice of the type of indicator itself is also normative. Indeed, conclusions on the same 
case may be different if the assessment focuses on vulnerability as expected cost or consider the consequences of the worst possible trajectories. For this reason, a study that uses several different vulnerability indicators may be more objective.

(4) Even in the absence of closed-form dynamics, the scope of a vulnerability assessment is related to $T$, the state space $\mathbb{X}$, the available policies $U_{a}(T)$, and the space $\Omega$ of all scenarios $W$. For instance, this tells which management policies, or which hazards and uncertainty sources, are being considered.

(5) A fully dynamic framework is a prerequisite to integrating the impact of policies in the assessment of vulnerability indicators, so as to understand how to best cope with a given situation. Even though a closed set of equations, let alone a way to optimize the implemented policy, may not be available often in practice, it should be kept in mind that implemented policies and adaptive actions dynamically influence vulnerability. 


\section{Acknowledgements}

This work has been supported by a Région Auvergne's scholarship. 


\section{A Probabilistic assumptions}

Let us assume that at each stage, $w(t) \in \mathbb{R}^{q}$, so that the scenario space $\Omega$ is a subset of $\left(\mathbb{R}^{q}\right)^{T}$, since a scenario $W$ is the $(T+1)$ - uplet $(w(0), w(1), \ldots, w(T))$. The first probabilistic assumption is to assume that $\Omega$ is equipped with a $\sigma$-field $\sigma(\Omega)$ and a probability $\mathbb{P}$. Thus, the triplet $(\Omega, \sigma(\Omega), \mathbb{P})$ is a probability space.

The second assumption consists in the possibility to define measurable and integrable probability distribution functions (pdf) over this probability space. Any pdf introduced in this work will be assumed to be measurable and integrable.

\section{B Viability maximization}

In what follows, for simplicity we discretize the state space into a discrete set which we note $\mathbb{X}_{d}$. Thus, we can define the transition probability from any state $x$ to any state $y$ given the control $u$. We note this function $p(x, y \mid u)$.

Let us have $K_{\theta}(t)$ as defined in equation (6), SDP works using a value function $G$ which is initialized at the final date $T$, then recursively updated backwards from $T$ to the initial date 0 . Initialization reads:

$$
G(T, x)=\left\{\begin{array}{lll}
1 & \text { if } & x \in K_{\theta}(T) \\
0 & \text { if } & x \notin K_{\theta}(T)
\end{array}\right.
$$

and the recursive transition equation is:

$$
\forall t \in[0, T-1], G(t, x)=\max _{u \in u_{a}(t, x)}\left(\sum_{y \in K_{\theta}(t)} p(x, y \mid u) G(t+1, y)\right)
$$

Doyen and De Lara (2010) prove that $G(0, x)$ is the maximal probability for the system to remain within $K_{\theta}(t)$ at all dates during $[0, T]$. 


\section{References}

Adger, W.N., 2006. Vulnerability. Global Environmental Change 16, 268-281.

Adger, W.N., Hugues, T.P., Folke, C., Carpenter, S.R., Rockström, J., 2005. Social-ecological resilience to coastal disasters. Science 309, 1036-1039.

Allen, C.R., Fontaine, J.J., Pope, K.L., Garmestani, A.S., 2011. Adaptive management for a turbulent future. Journal of Environmental Management 92, 1339-1345.

Anderies, J.M., Hegmon, M., 2011. Robustness and resilience across scales: Migration and resource degradation in the prehistoric u.s. southwest. Ecology and Society 16. 22.

Anderies, J.M., Rodriguez, A.A., Janssen, M.A., Cifdaloz, O., 2007. Panaceas, uncertainty, and the robust control framework in sustainability science. Proceedings of the National Academy of Science 104, 15194-15199.

Aubin, J.P., 1991. Viability Theory. Birkhäuser, Boston.

Balica, S., Popescu, I., Beevers, L., Wright, N., 2013. Parametric and physically based modelling techniques for flood risk and vulnerability assessment: A comparison. Environmental Modelling \& Software $41,84-92$.

Beck, G., Kropp, C., 2011. Infrastructures of risk: a mapping approach towards controversies on risks. Journal of Risk Research 14, 1-16.

Beklioglu, M., Romo, S., Kagalou, I., Quintana, X., Bécares, E., 2007. State of the art in the functioning of shallow mediterranean lakes: workshop conclusions. Hydrobiologia 584, 317-326.

Béné, C., Evans, L., Mills, D., Ovie, S., Raji, S., Tafida, A., Kodio, A., Sinaba, F., Morand, P., Lemoalle, J., Andrew, N., 2011. Testing resilience thinking in a poverty context: Experience from the niger river basin. Global Environmental Change 21, 1173-1184.

Béné, C., Wood, R.G., Newsham, A., Davies, M., 2012. Resilience: New Utopia or New Tyranny? Reflection about the Potentials and Limits of the Concept of Resilience in Relation to Vulnerability Reduction Programmes. IDS Working Paper 405. Institute of Development Studies.

Birkmann, J. (Ed.), 2006. Measuring vulnerability to natural hazards. United Nations University Press, Tokyo.

Brand, F.S., Jax, K., 2007. Focusing on the meaning(s) of resilience: Resilience as a descriptive concept and a boundary object. Ecology and Society 12.

Burton, I., 1997. Vulnerability and adaptive response in the context of climate and climate change. Climatic Change 36, 185-196.

Carpenter, S.R., 2008. Phosphorus control is critical to mitigating eutrophication. Proceedings of the National Academy of Science 105, 11039-11040. 
Carpenter, S.R., Folke, C., Scheffer, M., Westley, F., 2008. Resilience: Accounting for the noncomputable. Ecology and Society 14. 13.

Carpenter, S.R., Ludwig, D., Brock, W.A., 1999. Management of eutrophication for lakes subject to potentially irreversible change. Ecological Applications 9, 751-771.

Christiaensen, L.J., Boisvert, R.N., 2000. On measuring household food vulnerability: Case evidence from northern mali. Department of Agricultural, Resource, and Managerial Economics, Cornell University, Ithaca, New York.

Cobb, A.N., Thompson, J.L., 2012. Climate change scenario planning: A model for the integration of science and management in environmental decision-making. Environmental Modelling \& Software $38,296-305$.

Costa, L., Kropp, J.P., 2012. Linking components of vulnerability in theoretic frameworks and case studies. Sustainability Science 8, 1-9.

De Lara, M., Doyen, L., 2008. Sustainable Management of Natural Resources. Springer-Verlag, Berlin.

De Lara, M., Martinet, V., 2009. Multi-criteria dynamic decision under uncertainty: A stochastic viability analysis and an application to sustainable fishery management. Mathematical Biosciences $217,118-124$.

Deffuant, G., Gilbert, N. (Eds.), 2011. Viability and resilience of complex systems. Kluwer Academic Publishers, London.

Doyen, L., Béné, C., 2003. Sustainability of fisheries through marine reserves: a robust modeling analysis. Journal of Environmental Management 69, 1-13.

Doyen, L., De Lara, M., 2010. Stochastic viability and dynamic programming. Systems and Control Letters 59, 629-634.

Doyen, L., Thébaud, O., Béné, C., Martinet, V., Gourguet, S., Bertignac, M., Fifas, S., Blanchard, F., 2012. A stochastic viability approach to ecosystem-based fisheries management. Ecological Economics 75, 32-42.

Doyle, J., Francis, B., Tannenbaum, A., 1990. Feedback control Theory. Macmillan Publiching Co.

Eakin, H., Luers, A.L., 2006. Assessing the vulnerability of social-environmental systems. Annual Review of Environment and Resources 31, 365-394.

Esteves, L.S., 2013. Consequences to flood management of using different probability distributions to estimate extreme rainfall. Journal of Environmental Management 115, 98-105.

Felici, M., Lucarini, V., Speranza, A., Vitolo, R., 2007a. Extreme value statistics of the total energy in an intermediate-complexity model of the midlatitude atmospheric jet. part i: Stationary case. Journal of the Atmospheric Sciences 64, 2137-2158. 
Felici, M., Lucarini, V., Speranza, A., Vitolo, R., 2007b. Extreme value statistics of the total energy in an intermediate-complexity model of the midlatitude atmospheric jet. part ii: Trend detection and assessment. Journal of the Atmospheric Sciences 64, 2159-2175.

Folke, C., Carpenter, S., Elmqvist, T., Gunderson, L., Holling, C.S., Walker, B., Bengtsson, J., Berkes, F., Colding, J., Danell, K., Falkenmark, M., Gordon, L., Kasperson, R., Kautsky, N., Kinzig, A., Levin, S., Mäler, K.G., F.Moberg, Ohlsson, L., Olsson, P., Ostrom, E., Reid, W., Rockström, J., Savenije, H., Svedin, U., 2002. Resilience and Sustainable Development: Building Adaptive Capacity in a World of Transformations. Technical Report. Scientific Background Paper on Resilience for the process of The World Summit on Sustainable Development on behalf of The Environmental Advisory Council to the Swedish Government.

Folke, C.S., Carpenter, S., Walker, B., Scheffer, M., Elmqvist, T., Gunderson, L., Holling, C.S., 2004. Regime shifts, resilience, and biodiversity in ecosystem management. Annual Review of Ecology, Evolution, and Systematics 35, 557-581.

Foster, J., Greer, J., Thorbecke, E., 1984. A class of decomposable poverty measures. Econometrica $52,761-766$.

Fuchs, S., 2009. Susceptibility versus resilience to mountain hazards in austria - paradigms of vulnerability revisited. Natural Hazards and Earth System Sciences 9, 337-352.

Gallopín, G.C., 2006. Linkages between vulnerability, resilience, and adaptive capacity. Global Environmental Change 16, 293-303.

Giupponi, C., Giove, S., Giannini, V., 2013. A dynamic assessment tool for exploring and communicating vulnerability to floods and climate change. Environmental Modelling \& Software 44, 136 147. Thematic Issue on Innovative Approaches to Global Change Modelling.

Hashimoto, T., Stedinger, J.R., Loucks, D.P., 1982. Reliability, resiliency, and vulnerability criteria for water resource system performance evaluation. Water Resources Research 18, 14-20.

Hinkel, J., 2011. "indicators of vulnerability and adaptive capacity": Towards a clarification of the science-policy interface. Global Environmental Change 21, 198-208.

Hoddinott, J., Quisumbing, A., 2003. Methods for microeconometric risk and vulnerability assessments. Social Protection Discussion Paper 324. Washington DC: World Bank, Social Protection Unit Human Development Network.

Holling, C.S., 1973. Resilience and stability of ecological systems. Annual Review of Ecology, Evolution, and Systematics 4, 1-23.

Ionescu, C., Klein, R., Hinkel, J., Kumar, K.K., Klein, R., 2009. Towards a formal framework of vulnerability to climate change. Environmental Modelling and Assessment 14, 1-16.

Jeppesen, E., Kronvang, B., Meerhoff, M., Søndergaard, M., Hansen, K.M., Andersen, H.E., Lauridsen, T.L., Liboriussen, L., Beklioglu, M., Özen, A., Olesen, J.E., 2009. Climate change effects on runoff, 
catchment phosphorus loading and lake ecological state, and potential adaptations. Journal of Environmental Quality 38, 1930-1941.

Kasprzyk, J.R., Nataraj, S., Reed, P.M., Lempert, R.J., 2013. Many objective robust decision making for complex environmental systems undergoing change. Environmental Modelling \& Software 42, $55-71$.

Kjeldsen, T.R., Rosbjerg, D., 2004. Choice of reliability, resilience and vulnerability estimators for risk assessments of water resources systems. Hydrological Sciences Journal 49, 755-767.

Lardy, R., Bachelet, B., Bellocchi, G., Hill, D., 2014. Towards vulnerability minimization of grassland soil organic matter using metamodels. Environmental Modelling \& Software 52, 38 - 50.

Lesnoff, M., Corniaux, C., Hiernaux, P., 2012. Sensitivity analysis of the recovery dynamics of a cattle population following drought in the sahel region. Ecological Modelling 232, 28-39.

Liu, C., Golding, D., Gong, G., 2008. Farmers' coping response to the low flows in the lower yellow river: A case study of temporal dimensions of vulnerability. Global Environmental Change 18, $543-553$.

Loucks, D.P., 1997. Quantifying trends in system sustainability. Hydrological Sciences Journal 42, $513-530$.

Loucks, D.P., van Beek, E., 2005. Water Resources Systems Planning and Management. UNESCO.

Luers, A.L., 2005. The surface of vulnerability: An analytical framework for examining environmental change. Global Environmental Change 15, 214-233.

Luers, A.L., Lobell, D.B., Sklar, L.S., Addams, C.L., Matson, P.A., 2003. A method for quantifying vulnerability, applied to the agricultural system of the yaqui valley, mexico. Global Environmental Change 13, 255-267.

Martin, R., Linstädter, A., Frank, K., Müller, B., 2014. Livelihood security in face of drought assessing the vulnerability of pastoral households. Environmental Modelling \& Software, -.

Martin, S., 2004. The cost of restoration as a way of defining resilience: a viability approach applied to a model of lake eutrophication. Ecology and Society 9 .

McCarthy, J.J., Canziani, O.F., Leary, N.A., Dokken, D.J., White, K.S. (Eds.), 2001. Climate Change 2001: Impacts, Adaptation and Vulnerability. Cambridge University Press, Cambridge.

McCulloch, N., Calandrino, M., 2003. Vulnerability and chronic poverty in rural sichuan. World Development 31, 611-628.

McDowell, J.Z., Hess, J.J., 2012. Accessing adaptation: Multiple stressors on livelihoods in the bolivian highlands under a changing climate. Global Environmental Change 22, 342-352.

Mendoza, V.M., Villanueva, E.E., Adem, J., 1997. Vulnerability of basins and watersheds in mexico to global climate change. Climate Research 9, 139-145. 
Menoni, S., Pergalani, F., Boni, M.P., Petrini, V., 2002. Lifelines earthquake vulnerability assessment: a systemic approach. Soil Dynamics and Earthquake Engineering 22, 1199-1208.

Miller, F., Osbahr, H., Boyd, E., Thomalla, F., Bharwani, S., Ziervogel, G., Walker, B., Birkmann, J., van der Leeuw, S., Rockström, J., Hinkel, J., Downing, T., Folke, C., Nelson, D., 2010. Resilience and vulnerability: Complementary or conflicting concepts? Ecology and Society 15. 11.

Moy, W., Cohon, J., ReVelle, C., 1986. A programming model for analysis of the reliability, resilience, and vulnerability of a water supply reservoir. Water Resources Research 22, 489-498.

Nelson, D.R., Adger, W.N., Brown, K., 2007. Adaptation to environmental change: contributions of a resilience framework. Annual Review of Environment and Resources 32, 395-419.

Papathoma-Köhle, M., Zischg, A., Fuchs, S., Glade, T., Keiler, M., 2015. Loss estimation for landslides in mountain areas - an integrated toolbox for vulnerability assessment and damage documentation. Environmental Modelling \& Software 63, 156 - 169.

Parry, M., Canziani, O., Palutikof, J., van der Linden, P., Hanson, C. (Eds.), 2007. Climate Change 2007: Impacts, Adaptation and Vulnerability. Contribution of Working Group II to the Fourth Assessment Report of the Intergovernmental Panel on Climate Change. Cambridge University Press, Cambridge, United Kingdom and New York, NY, USA.

Peduzzi, P., Dao, H., Herold, C., Mouton, F., 2009. Assessing global exposure and vulnerability towards natural hazards: the disaster risk index. Natural Hazards and Earth System Sciences 9, $1149-1159$.

Peterson, G.D., 2002. Estimating resilience across landscapes. Ecology and Society 6. 17.

Preston, B.L., 2013. Local path dependence of u.s. socioeconomic exposure to climate extremes and the vulnerability commitment. Global Environmental Change 23, 719-732.

Rives, F., Antona, M., Aubert, S., 2012. Social-ecological functions and vulnerability framework to analyze forest policy reforms. Ecology and Society 17. 21.

Rockström, J., Falkenmark, M., Lannerstad, M., Karlberg, L., 2012. The planetary water drama: Dual task of feeding humanity and curbing climate change. Geophysical Research Letters 39.

Rodriguez, A.A., Cifdaloz, O., Anderies, J.M., Janssen, M.A., Dickeson, J., 2011. Confronting management challenges in highly uncertain natural resource systems: a robustness-vulnerability trade-off approach. Environmental Modelling \& Assessment 16, 15-36.

Rodríguez-Blanco, M., Taboada-Castro, M., Taboada-Castro, M., 2013. Phosphorus transport into a stream draining from a mixed land use catchment in galicia (nw spain): Significance of runoff events. Journal of Hydrology 481, 12-21.

Rougé, C., Mathias, J.D., Deffuant, G., 2013. Extending the viability theory framework of resilience to uncertain dynamics, and application to lake eutrophication. Ecological Indicators 29, 420-433. 
Sabatier, R., Doyen, L., Tichit, M., 2010. Modelling trade-offs between livestock grazing and wader conservation in a grassland agroecosystem. Ecological Modelling 221, 1292-1300.

Sandoval-Solis, S., McKinney, D.C., Loucks, D.P., 2011. Sustainability index for water resources planning and management. Journal of Water Resources Planning and Management 137, 381-390.

Schindler, D.W., 2006. Recent advances in the understanding and management of eutrophication. Limnology and Oceanography 51, 356-363.

Schindler, D.W., Hecky, R.E., Findlay, D.L., Stainton, M.P., Parker, B.R., Paterson, M.J., Beaty, K.G., Lyng, M., Kasian, S.E.M., 2008. Eutrophication of lakes cannot be controlled by reducing nitrogen input: Results of a 37-year whole-ecosystem experiment. Proceedings of the National Academy of Science 105, 11254-11258.

Schoon, M., Fabricius, C., Anderies, J.M., Nelson, M., 2011. Synthesis: Vulnerability, traps, and transformations - long-term perspectives from archaeology. Ecology and Society 16. 24.

Sharpley, A.N., Kleinman, P.J.A., Heathwaite, A.L., Gburek, W.J., Folmar, G.J., Schmidt, J.P., 2008. Phosphorus loss from an agricultural watershed as a function of storm size. Journal of Environmental Quality $37,362-368$.

Smit, B., Burton, I., Klein, R., Wandel, J., 2000. An anatomy of adaptation to climate change and variability. Climatic Change 45, 223-251.

Smit, B., Wandel, J., 2006. Adaptation, adaptive capacity and vulnerability. Global Environmental Change 16, 282-292.

Swanson, D., Barg, S., Tyler, S., Venema, H., Tomar, S., Bhadwal, S., Nair, S., Roy, D., Drexhage, J., 2010. Seven tools for creating adaptive policies. Technological Forecasting and Social Change 77, 924-939.

Turner II, B.L., Kasperson, R.E., Matson, P.A., McCarthy, J.J., Corell, R.W., Christensen, L., Eckley, N., Kasperson, J.X., Luers, A., Martello, M.L., Polsky, C., Pulsipher, A., Schiller, A., 2003. A framework for vulnerability analysis in sustainability science. Proceedings of the National Academy of Science 100, 8074-8079.

Webby, R., Adamson, P., Boland, J., Howlett, P., Metcalfe, A., Piantadosi, J., 2007. The mekong applications of value at risk (var) and conditional value at risk (cvar) simulation to the benefits, costs and consequences of water resources development in a large river basin. Ecological Modelling 201, 89-96.

Wolf, S., Hinkel, J., Hallier, M., Bisaro, A., Lincke, D., Ionescuo, C., Klein, R.J.T., 2013. Clarifying vulnerability definitions and assessments using formalisation. International Journal of Climate Change Strategies and Management 5, 54-70.

Yohe, G., Tol, R., 2002. Indicators for social and economic coping capacity - moving toward a working definition of adaptive capacity. Global Environmental Change 12, 25-40.

Zhou, K., Doyle, J., 1998. Essentials of Robust Control. Prentice Hall. 